\title{
Dynamics of Glomerular Ultrafiltration in the Rat
}

\author{
V. RESPONSE TO ISCHEMIC INJURY \\ Terrance M. Daugharty, Iris F. Ueki, Paul F. Mercer, and \\ BARRY M. BRENNER \\ From the Departments of Medicine, Veterans Administration Hospital, \\ San Francisco, California and the University of California, \\ San Francisco, California 94121
}

A B S T R A C T An experimental model of postischemic, acute renal failure has been developed in Wistar rats with surface glomeruli, thereby making possible a direct assessment of the mechanisms responsible for the fall in glomerular filtration rate that characterizes this disorder. Whole kidney and cortical single nephron filtration rates were reduced proportionately, on average by approximately $40 \%$, after $3 \mathrm{~h}$ of nearly complete occlusion of the ipsilateral renal artery. The possibility of a significant transtubular leak of inulin was excluded. This decline in filtration rate occurred in the absence of measured changes in mean arterial pressure, mean glomerular transcapillary hydrostatic pressure, or net ultrafiltration pressure at afferent and efferent ends of the glomerular capillary. Net ultrafiltration pressure at the efferent end of the capillary approached zero both before and after ischemic injury, demonstrating that filtration pressure equilibrium was achieved throughout this study. Single nephron filtration fraction remained unchanged, indicating that the fall in filtration rate was accompanied by a proportional decline in glomerular plasma flow. The results indicate that the fall in filtration rate was solely the consequence of this fall in glomerular plasma flow. Since filtration rate per nephron is equal to the product of the ultrafiltration coefficient and mean ultrafiltration pressure, this product must also have fallen in proportion to the decline in glomerular plasma flow. Evidence is presented to indicate that a change in ultrafiltration coefficient is not required to

This work has been published in abstract form. 1973. Clin. Res. $21: 227$.

Dr. Brenner is a Medical Investigator and Dr. Daugharty a Clinical Investigator of the Veterans Administration. Dr. Mercer was on sabpatical leave from the Department of Physiology, the University of Western Ontario, London, Canada.

Received for publication 12 June 1973 and in revised form 4 September 1973. account for the observed fall in filtration rate. The reduction in glomerular plasma flow, occurring in the absence of a concomitant decline in mean glomerular capillary hydrostatic pressure, resulted from large and proportional increases in afferent and efferent arteriolar resistances. These resistance changes appear to play a fundamental role in the pathogenesis of this form of acute renal failure.

\section{INTRODUCTION}

Despite the frequency with which acute renal failure is encountered in clinical medicine and the relative ease with which this disorder can be reproduced experimentally, the mechanism(s) responsible for the reduction in glomerular filtration rate, one of the hallmark features of this disorder, has yet to be clearly delineated. This is not entirely surprising in that, until recently, a quantitative formulation of the pressures and flows governing ultrafiltration has been lacking, owing to the extreme infrequency with which glomeruli are encountered as accessible surface structures in the mammal. This limitation to the direct study of the dynamics of glomerular transcapillary fluid exchange has been overcome in the past few years, however, largely as a consequence of the discovery of a mutant strain of Wistar rats (the so-called Munich-Wistar strain [1] ) possessing surface glomeruli. Recent studies from this laboratory, employing this unique strain of rats, together with highly sensitive servo-null micropressure transducers and ultramicroprotein assay methods, have provided a considerable body of data (1-4) which not only serves to characterize glomerular dynamics in the physiologically normal rat, but which can also provide a much needed frame of reference against which to compare a number of clinically relevant, experimentally induced disorders of glomerular function. 
The present study was undertaken in an effort to gain insight into one such disorder, namely, an experimental model of acute, postischemic renal failure, and to apply appropriate techniques to characterize the glomerular transcapillary forces responsible for the accompanying decline in glomerular filtration rate.

\section{GLOSSARY OF SYMBOLS}

\begin{tabular}{|c|c|}
\hline & \\
\hline$\overline{A P}$ & Mean femoral arterial pressure, $\mathrm{mm} \mathrm{Hg}$. \\
\hline$\triangle B F$ & Protein concentration, $\mathrm{g} / 100 \mathrm{ml}$. \\
\hline $\begin{array}{l}\text { EABF } \\
\text { GBF, GPF }\end{array}$ & $\begin{array}{l}\text { Efferent arteriolar blood tlow, } \mathrm{nl} / \mathrm{min} \text {. } \\
\text { Glomerular blood flow and plasma flow, re- } \\
\text { spectively, } \mathrm{nl} / \mathrm{min} \text {. }\end{array}$ \\
\hline $\operatorname{Hct}_{\boldsymbol{A}}$ & $\begin{array}{l}\text { Blood hematocrit in femoral artery or afferent } \\
\text { arteriole. }\end{array}$ \\
\hline$k$ & $\begin{array}{l}\text { Effective hydraulic permeability, } \mathrm{nl} /(\mathrm{s} \cdot \mathrm{mm} \\
\left.\mathrm{Hg} \cdot \mathrm{cm}^{2}\right) \text {. }\end{array}$ \\
\hline$K_{f}$ & $\begin{array}{l}\text { Ultrafiltration coefficient, } \mathrm{nl} /(\mathrm{s} \cdot \mathrm{mm} \quad \mathrm{Hg}) \text { or } \\
\mathrm{nl} /(\mathrm{min} \cdot \mathrm{mm} \mathrm{Hg}) \text {. }\end{array}$ \\
\hline$P$ & Hydrostatic pressure, $\mathrm{mm} \mathrm{Hg}$. \\
\hline$P_{U F}$ & Net ultrafiltration pressure, $\mathrm{mm} \mathrm{Hg}$. \\
\hline$\Delta P$ & $\begin{array}{l}\text { Transmembrane hydrostatic pressure difference, } \\
P_{G C}-P_{T}, \mathrm{~mm} \mathrm{Hg} \text {. }\end{array}$ \\
\hline$\pi$ & Colloid osmotic pressure, $\mathrm{mm} \mathrm{Hg}$. \\
\hline$\Delta \pi$ & $\begin{array}{l}\text { Transmembrane osmotic pressure difference, } \\
\pi_{G C}-\pi_{T}, \mathrm{~mm} \mathrm{Hg} \text {. }\end{array}$ \\
\hline$R$ & Resistance to blood flow, $\mathrm{dyn} \cdot \mathrm{s} \cdot \mathrm{cm}^{-5}$. \\
\hline$R_{T A}$ & $\begin{array}{l}\text { Total arteriolar resistance, } R_{A}+R_{E} \text {, dyn. } \\
\mathrm{s} \cdot \mathrm{cm}^{-5} \text {. }\end{array}$ \\
\hline$S$ & Surface area available for ultrafiltration, $\mathrm{cm}^{2}$. \\
\hline SNFF & Single nephron filtration fraction. \\
\hline SNGFR & Single nephron glomerular filtration rate, $\mathrm{nl} / \mathrm{min}$. \\
\hline $\begin{array}{l}(1 \mathrm{~F} / \\
V_{T F}\end{array}$ & $\begin{array}{l}\text { Tubule fluid flow rate, } \mathrm{nl} / \mathrm{min} \text {. } \\
\text { SuPERSCRIPT }\end{array}$ \\
\hline - & Mean value. \\
\hline & SUBSCRIPTS \\
\hline $\begin{array}{l}A \\
C \\
E \\
G C \\
T\end{array}$ & $\begin{array}{l}\text { Afferent arteriole. } \\
\text { Peritubular capillary. } \\
\text { Efferent arteriole. } \\
\text { Glomerular capillary. } \\
\text { Proximal tubule. }\end{array}$ \\
\hline
\end{tabular}

\section{METHODS}

Experiments were performed in Munich-Wistar rats ranging in weight from $161-320 \mathrm{~g}$. Each rat was allowed free access to water and a standard rat pellet diet until the morning of study. After anesthetization with Inactin intraperitoneally ( $100 \mathrm{mg} / \mathrm{kg}$ body weight) the rat was placed on a temperature-regulated micropuncture table and prepared for clearance and/or micropuncture study in the manner previously described for this laboratory (1-6). In addition to this routine preparation, a loose snare of surgical silk was inserted so as to encircle the left renal artery for subsequent use in reducing blood flow to the left kidney. About $15 \mathrm{~min}$ before completion of surgery, a continuous intravenous infusion of $10 \%$ inulin in isotonic saline was begun at the rate of $0.02 \mathrm{ml} / \mathrm{min}$. This resulted in plasma inulin concentrations of approximately $1 \mathrm{mg} / \mathrm{ml}$.

Effect of $3 h$ of partial left renal arterial occlusion on GFR and urine composition. The effects of $3 \mathrm{~h}$ of severe ischemia on whole kidney (GFR) and cortical single nephron (SNGFR) glomerular filtration rates were examined in seven rats. Beginning $45 \mathrm{~min}$ after completion of surgery, three to five collections of urine were obtained from each kidney for determination of volume flow rate and inulin concentration. Simultaneously, two to four exactly timed (1-2 $\mathrm{min}$ ) total collections of proximal tubule fluid were obtained from surface nephrons in the left kidney for determination of volume flow rate and inulin concentration. In four of these rats, tubule fluid collections were obtained from randomly selected segments of surface proximal tubules; in the remaining three and in two additional rats not otherwise studied, collections of tubule fluid were obtained from either first or last accessible segments of surface proximal tubules. These first and last segments, examined to determine whether inulin leaks out of proximal tubules as a result of ischemic injury, were identified by observing the passage of lissamine green which was injected rapidly $(0.04 \mathrm{ml}$ of a $5 \%$ solution) into the left jugular vein. Tubule fluid was collected with sharpened micropipettes (8-12 $\mu \mathrm{m} \mathrm{OD})$, using the technique of controlled suction previously validated for this laboratory (7). In addition, two to three samples of femoral arterial blood were obtained for determination of hematocrit and plasma inulin concentration. Femoral arterial blood pressure $(\overrightarrow{A P})$ was monitored using a pressure transducer (model P23A.A, Statham Instruments, Inc., Oxnard, Calif.) attached to an electronic recorder (model 7712, HewlettPackard Co., Palo Alto, Calif.).

Following these control observations, the left renal arterial snare was tightened progressively until arterial pulsations distal to the snare were abolished and the gross appearance of the kidney became shrunken, pale, and slightly cyanotic. These changes were accompanied by uniform collapse of all surface tubule segments and by cessation of urine flow. In all instances, the degree of occlusion of the left renal artery was carefully monitored to insure that blood flow was not completely abolished, but only drastically reduced. As an end point, blood flow in surface peritubular capillaries was reduced to a degree sufficient to slow markedly, but not abolish, the movement of erythrocytes through the capillaries. That glomerular filtration had indeed ceased was verified by the intravenous injection of lissamine green. Dye uniformly failed to appear in surface nephrons during the ischemic period. Occlusion was maintained for exactly $3 \mathrm{~h}$ in each rat. During occlusion the microscopic appearance of the surface of the kidney was monitored repeatedly and the above described alterations in appearance and function were maintained unchanged.

At the end of this $3 \mathrm{~h}$ period of ischemia the occluding snare was removed. Vigorous renal arterial pulsations returned almost immediately and, within the subsequent 10-15 min, kidney size and surface capillary blood flow appeared to return toward normal. In this same period of time, surface nephrons were noted to fill with fluid and urine formation was noted to resume. Since the infusion of inulin was withheld during the period of occlusion, priming and sustaining infusions of $10 \%$ inulin in isotonic saline were readministered at rates which yielded final plasma inulin concentrations of approximately $1 \mathrm{mg} / \mathrm{ml}$. These repeat infusions of inulin were begun within $5 \mathrm{~min}$ of release of renal arterial constriction. After $20 \mathrm{~min}$ of equilibration, measurements of GFR were repeated for left (clamped) and right (unclamped) kidneys in each rat, the latter values serving as the time control for the former. Concurrently, samples of proximal tubule fluid were recollected from sites previously punctured, for repeat determination of 
SNGFR. To obtain a similar time control for SNGFR determinations, we elected not to study the right (unciamped) kidney in comparison to the left, but rather to repeat the protocol in other rats exactly as described above with the exception that the left renal artery was not clamped. A separate group of four rats was employed for this purpose, with two to four late proximal tubules being studied in each rat before and after sham occlusion of the left renal artery. Again the recollection micropuncture technique was employed.

A second method for evaluating the validity of the use of inulin as an ideal marker of glomerular ultrafiltration in the postischemic kidney was based on the recovery in urine of $\left[{ }^{3} \mathrm{H}\right]$ inulin microinjected into surface proximal tubules, according to the method of Gottschalk, Morel, and Mylle (8). In each of three rats, both ureters were catheterized with PE 50 tubing. To permit rapid serial urine collections, rats were made diuretic by intravenous infusion of furosemide $(1 \mathrm{mg} / \mathrm{kg}$ prime and $/ \mathrm{h})$. Approximately 5 nl of $\left[{ }^{3} \mathrm{H}\right]$ inulin (New England Nuclear Corp., Boston, Mass.) in nigrosin-stained isotonic saline was used for microinjection into early and midproximal segments, identified with the aid of lissamine green. Injections were made at rates slow enough to prevent retrograde flow. Ureteral urine was collected into $1-\mathrm{ml}$ cylinders graduated in units of $0.01 \mathrm{ml}$. Urine collections were started at the beginning of each microinjection. Three consecutive $10-\mathrm{min}$ collections were made from each catheter. To each sample of collected urine was added sufficient cold urine to bring the volume to $1.0 \mathrm{ml}$. Cold urine was obtained before isotope injections. Calibration droplets equal in volume to the volumes microinjected were deposited into $1.0 \mathrm{ml}$ of cold urine to serve as reference standards. Reference standards and experimental urine samples were each washed with 7 $\mathrm{ml}$ of Aquasol (New England Nuclear Corp.) into vials containing $2 \mathrm{ml}$ of distilled water and mixed thoroughly. This liquid scintillation counting mixture formed a gel which prevented settling of isotope. Radioactivity was measured in a liquid scintillation counter (model 3380, Packard Tri-Carb, Packard Instrument Co., Inc., Downers Grove, IIl.). Samples were counted for $50 \mathrm{~min}$ or for a total of 10,000 counts above background. Reference standards always reached 10,000 counts above background.

Glomerular dynamics before and after ischemic injury. In 10 additional rats the effects of $3 \mathrm{~h}$ of left renal ischemia on the glomerular transcapillary determinants of ultrafiltration were studied. In these rats, beginning about $45 \mathrm{~min}$ after completion of surgery, exactly timed (1-2 min) total collections of fluid were obtained from late segments of two to four surface proximal tubules for determination of volume flow rate and inulin concentration. Simultaneously, two to three samples of femoral arterial blood were obtained for measurement of hematocrit and plasma inulin and protein concentrations. The concentrations of these substances are taken as equal to their concentrations in afferent arteriolar plasma. In addition, samples of blood from two to three surface efferent arterioles were obtained for determination of postglomerular plasma protein concentration. $\overline{A P}$ was monitored throughout. Hydrostatic pressures within single capillaries of surface glomeruli $\left(\bar{P}_{G C}\right),{ }^{1}$ peritubule capillaries $\left(P_{c}\right)$, and proximal tubules

${ }^{1}$ The values for $P_{G C}$ reported in the present study represent time averages. The term $\bar{P}_{G C}$ represents $P_{G C}$ averaged over the length of the glomerular capillary, the justification for which has been discussed previously (2).
$\left(P_{T}\right)$ were measured using continuous recording, electronic servo-null micropressure transducer techniques (9-11). For these measurements, $0.5 \mathrm{M} \mathrm{NaCl-containing} \mathrm{micro-}$ pipettes with outer tip diameters of $2-3 \mu \mathrm{m}$ were used, and capillary entry was accomplished under stereomicroscopic control. Hydraulic output from the servo system was coupled electronically to a second channel of the HewlettPackard recorder by means of a pressure transducer (model P23Db, Statham Instruments, Inc.). Accuracy, frequency response, and stability features of this servo system have been described in detail previously (11).

After completion of these measurements, the left renal artery was nearly completely occluded for $3 \mathrm{~h}$, in the manner already described. Thereafter, the occlusion was relieved and each of the above measurements repeated. Repeat collections of proximal tubule fluid were obtained using recollection techniques. Repeat collections of efferent arteriolar blood and measurements of $P_{\boldsymbol{c}}$ and $P_{\boldsymbol{T}}$ were obtained from sites not previously punctured. In many rats, since only one glomerulus was present on the kidney surface, repeat measurements of $\bar{P}_{G C}$ necessitated entry into capillaries of a previously punctured glomerulus.

Analytical techniques. The volume of fluid collected from individual proximal tubules was determined from the length of the fluid column in a constant-bore capillary tube of known internal diameter. The concentration of inulin in tubule fluid was measured, usually in duplicate, by the microfluorescence method of Vurek and Pegram (12). Inulin concentration in plasma was determined by the macroanthrone method of Führ, Kaczmarczyk, and Krüttgen (13). Protein concentration in efferent arteriolar $\left(C_{E}\right)$ and femoral arterial $\left(C_{A}\right)$ blood plasma was determined, usually in duplicate, with an ultramicrocolorimeter ${ }^{2}$ using a recently described microadaptation (14) of the method of Lowry, Rosebrough, Farr, and Randall (15).

Calculations. SNGFR:

$$
\mathrm{SNGFR}=(\mathrm{TF} / \mathrm{P})_{I N} \cdot V_{T \boldsymbol{T}}
$$

where $(\mathrm{TF} / \mathrm{P})_{I N}$ and $V_{T F}$ refer to the tubule fluid to plasma inulin concentration ratio and tubule fluid flow rate, respectively.

Single nephron filtration fraction (SNFF):

$$
\mathrm{SNFF}=1-\frac{C_{A}}{C_{E}}
$$

where $C_{A}$ and $C_{E}$ denote afferent and efferent arteriolar plasma protein concentrations, respectively.

Volume flow rate of plasma entering the glomerulus. glomerular plasma flow (GPF) :

$$
\mathrm{GPF}=\frac{\mathrm{SNGFR}}{\mathrm{SNFF}}
$$

Glomerular blood flow (GBF) :

$$
\mathrm{GBF}=\frac{\mathrm{GPF}}{1-\operatorname{Hct}_{A}}
$$

where $\mathrm{Hct}_{A}$, the hematocrit of afferent arteriolar blood, is taken as being equal to femoral arterial hematocrit.

${ }^{2}$ Designed and constructed by Dr. Gerald Vurek, Laboratory of Technical Development, National Heart and Lung Institute, Bethesda, Md.

Glomerular Dynamics in Acute Renal Failure 107 
Efferent arteriolar blood flow :

$$
\mathrm{EABF}=\mathrm{GBF}-\mathrm{SNGFR}
$$

Resistance per single afferent arteriole:

$$
R_{A}=\frac{\overline{A P}-\bar{P}_{G C}}{\mathrm{GBF}} \times\left(7.962 \times 10^{10}\right)
$$

where the factor $7.962 \times 10^{10}$ is used to give resistance in units of dyn $\cdot \mathrm{s} \cdot \mathrm{cm}^{-5}$ when $\overline{A P}$ and $\bar{P}_{G C}$ are expressed in $\mathrm{mm}$ $\mathrm{Hg}$ and $\mathrm{GBF}$ in $\mathrm{nl} / \mathrm{min}$.

Resistance per single efferent arteriole:

$$
R_{E}=\frac{\bar{P}_{G C}-P_{C}}{\mathrm{EABF}} \times\left(7.962 \times 10^{10}\right)
$$

Total arteriolar resistance for a single pre- to postglomerular vascular unit :

$$
R_{T A}=R_{A}+R_{E}
$$

Estimates of the net ultrafiltration pressure $\left(P_{U F}\right)$ at the afferent- and efferent-most portions of the glomerular capillary : ${ }^{3}$

$$
\begin{aligned}
& P_{U F_{A}}=\bar{P}_{G C}-P_{T}-\pi_{A} \\
& P_{U F_{B}}=\bar{P}_{G C}-P_{T}-\pi_{E}
\end{aligned}
$$

where $\pi_{A}$ and $\pi_{E}$, afferent and efferent arteriolar colloid osmotic pressures, were calculated from femoral arterial and efferent arteriolar plasma protein concentrations using the Landis-Pappenheimer equation (16). Equations 9 and 10 contain the assumption that the colloid osmotic pressure of fluid in Bowman's space $\left(\pi_{T}\right)$ is negligible. This assumption has been validated by the finding that the protein concentration of fluid in Bowman's space, both before and after $3 \mathrm{~h}$ of renal ischemia, is less than $200 \mathrm{mg} / 100$ $\mathrm{ml}$. Accordingly, $\pi_{T}$ is well below $1 \mathrm{~mm} \mathrm{Hg}$.

Mean net glomerular transcapillary hydrostatic pressure:

$$
\overrightarrow{\Delta P}=P_{G C}-P_{T}
$$

The percent recovery of injected $\left[{ }^{3} \mathrm{H}\right]$ inulin:

Percent recovery $=\frac{\left[{ }^{3} \mathrm{H}\right] \text { inulin in urine }}{\left[{ }^{3} \mathrm{H}\right] \text { inulin in injectate }} \times 100$

\section{RESULTS}

Evaluation of inulin as a valid marker of GFR after renal ischemia. Justification for the use of inulin as an ideal marker of GFR after ischemic injury was obtained from two sets of evidence. First we compared absolute values of SNGFR in first and last segments of surface proximal tubules as well as percentage changes in recollection values of SNGFR at these sites. Before ischemia, values for SNGFR averaged 36.5 $\pm 3.7 \mathrm{SE} \mathrm{nl} / \mathrm{min}(n=5)$ and $34.6 \pm 3.9$ (5) at first and last accessible segments, respectively $(P>$ $0.5)$. After ischemia, values at these respective sites

${ }^{3}$ The use of this equation assumes the axial variation in $P_{a c}$ to be negligible. The justification for this assumption is discussed in detail elsewhere (2). averaged $17.1 \pm 4.1 \mathrm{nl} / \mathrm{min}$ and $15.6 \pm 4.7$. These reductions in SNGFR were uniform and highly significant $(P<0.001)$, averaging $56 \pm 8$ and $58 \pm 10 \%$, respectively, but were not significantly different from one another $(P>0.5)$. A comparison of paired changes in SNGFR (postocclusion vs. preocclusion) at first vs. last sites in each rat is shown in Fig. 1. It can be seen that comparable reductions obtained at first and last collection sites irrespective of the magnitude of the decline in SNGFR. The ratio $\triangle \mathrm{SNGFR}$ first segment/ $\triangle \mathrm{SNGFR}$ last segment averaged $0.97 \pm 0.04$, a value not significantly different from unity $(P>0.4)$. Moreover, changes in SNGFR after ischemia were essentially identical to changes in whole kidney GFR, averaging $49 \pm 5(7)$ and $52 \pm 8 \%(7)$, respectively $(P>0.5)$.

The second set of evidence justifying the use of inulin as a valid glomerular marker was obtained from proximal tubule microinjection studies. Six microinjections of $\left[{ }^{3} \mathrm{H}\right]$ inulin were performed in three rats after ischemic injury. Ipsilateral recoveries of $\left[{ }^{3} \mathrm{H}\right]-$ inulin were essentially complete after microinjection, averaging 101 $\pm 1 \%$ (range: 98-106\%). Recovery from the contralateral kidney was never in excess of background. This evidence demonstrating impermeability of the tubule epithelium to inulin after ischemic injury was obtained in experimental kidneys in which whole kidney inulin clearances were reduced by 24,36 , and $39 \%$ for the three rats studied. Since microinjected $\left[{ }^{3} \mathrm{H}\right]$ inulin was essentially completely recovered, these reductions in whole kidney clearances of inulin could only have occurred as a result of true reductions in GFR.

Effects of $3 h$ of unilateral renal ischemia on GFR and urine composition. Table I summarizes average values for $\overline{A P}$, systemic hematocrit, as well as GFR, urine flow, urine/plasma inulin concentration ratios,

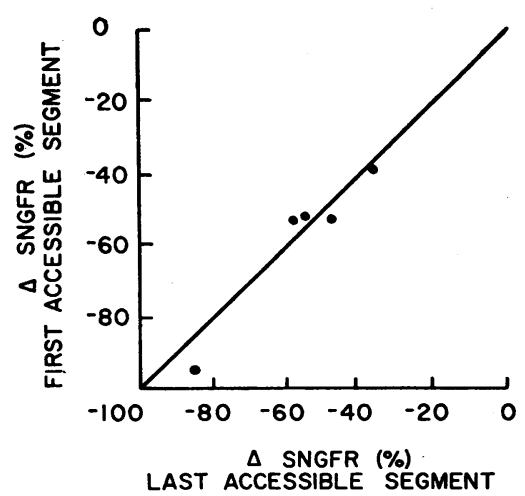

FIGURE 1 Comparison of percentage changes in SNGFR measured at first and last accessible proximal tubule segment collection sites before and after ischemic injury in individual rats. 
TABLE I

Effect of 3 h of Left Renal Ischemia on Bilateral Renal Function

\begin{tabular}{|c|c|c|c|c|c|c|c|c|c|c|c|}
\hline & \multirow[b]{2}{*}{$\overline{A P}$} & \multirow[b]{2}{*}{ Hct } & \multicolumn{5}{|c|}{ Left kidney } & \multicolumn{4}{|c|}{ Right kidney } \\
\hline & & & SNGFR & GFR & $\begin{array}{l}\text { Urine } \\
\text { flow }\end{array}$ & $\left(\frac{\mathrm{U}}{\mathrm{P}}\right)_{I N}$ & $\mathrm{U}_{[\mathrm{Na}]}$ & GFR & $\begin{array}{l}\text { Urine } \\
\text { flow }\end{array}$ & $\left(\frac{\mathrm{U}}{\mathrm{P}}\right)_{I N}$ & $\mathrm{U}_{[\mathrm{Na}]}$ \\
\hline & $m m ~ H g$ & $\%$ & $n l / \min$ & $m l / m i n$ & $\mu l / m i n$ & & meq/liter & $\mathrm{ml} / \mathrm{min}$ & $\mu l / \min$ & & meq/liler \\
\hline \multicolumn{12}{|c|}{ Preleft renal ischemia } \\
\hline Mean & 106 & 52 & 33 & 0.84 & 3.7 & 213 & 56.4 & 0.91 & 4.2 & 2.30 & 66.2 \\
\hline$\pm \mathrm{SE}$ & 3 & 1 & 3 & 0.07 & 0.8 & 16 & 12.5 & 0.03 & 0.2 & 9 & 13.1 \\
\hline $\mathrm{N}$ rats & 7 & 7 & 7 & 7 & 7 & 7 & 5 & 5 & 5 & 5 & 5 \\
\hline \multicolumn{12}{|c|}{ Postleft renal ischemia } \\
\hline Mean & 102 & 52 & 17 & 0.41 & 4.4 & 99 & 132.8 & 0.99 & 5.3 & 189 & 151.2 \\
\hline$\pm \mathrm{SE}$ & 2 & 1 & 3 & 0.08 & 0.9 & 10 & 28.0 & 0.08 & 0.2 & 9 & 32.4 \\
\hline $\mathrm{N}$ rats & 7 & 7 & 7 & 7 & 7 & 7 & 5 & 5 & 5 & 5 & 5 \\
\hline Mean $\Delta, \%$ & -3.2 & +0.2 & -48.6 & -51.7 & +10.8 & -52.6 & +141 & +10.5 & +28.7 & -16.8 & +126 \\
\hline$\pm \mathrm{SE}$ & 3.1 & 1.4 & 5.1 & 8.4 & 20.7 & 4.9 & 43 & 11.6 & 6.6 & 5.8 & 14 \\
\hline$P$ Value & $>0.2$ & $>0.5$ & $<0.001$ & $<0.001$ & $>0.5$ & $<0.001$ & $<0.05$ & $>0.5$ & $<0.001$ & $<0.05$ & $<0.001$ \\
\hline
\end{tabular}

and urinary sodium concentrations for left (experimental) and right (control) kidneys both before and after left renal ischemia. Mean values of SNGFR for the experimental kidney are also given. $\overline{A P}$ and Hct remained essentially unchanged. For these seven rats, ischemia resulted in uniform declines in SNGFR averaging $49 \%$, which, as already noted, paralleled declines in whole kidney GFR. That these declines in filtration rate were the specific consequence of temporary renal ischemia is given by the findings $(a)$ that values for GFR for the nonclamped right kidney failed to exhibit similar declines, changing on average by $+10.5 \pm 11.6 \%(P>0.5)$, and $(b)$ values for SNGFR in four rats subjected to sham clamping of the left renal artery changed (relative to presham-clamped control values $)$ by an average of $-3.6 \pm 7.6 \% \quad(n=16$ nephrons $)(P>0.5)$.

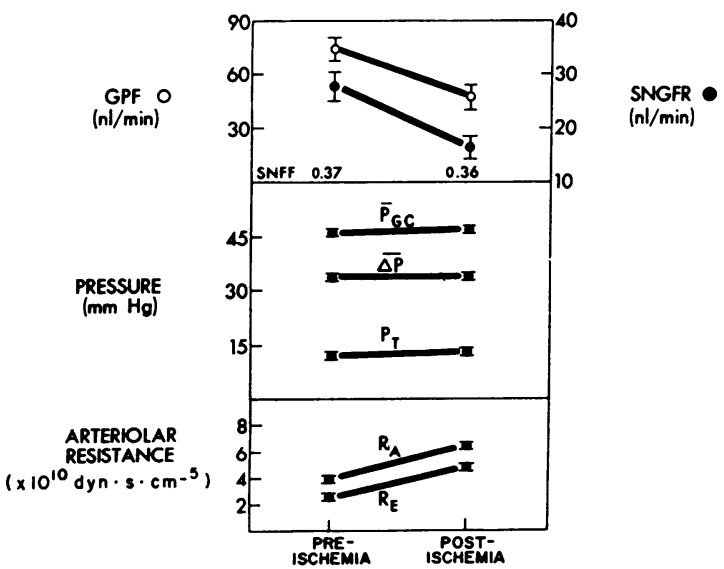

FIGURE 2 Summary of effects of ipsilateral ischemic injury on several measures of surface nephron and microvascular function.
As shown in Table I, temporary ischemia of the left kidney was associated with a large decline in ipsilateral fractional water reabsorption ( $\mathrm{U} / \mathrm{P}$ inulin concentration declined an average of $53 \%$ ). As a result, despite the large fall in filtration rate, urine flow remained relatively unchanged. While a statistically significant decline in the mean $U / P$ inulin concentration ratio was measured on the nonclamped side, the magnitude of this decline tended to be small. For individual rats, $\mathrm{U} / \mathrm{P}$ inulin ratios for the right kidney ranged from 177-285 before to 144-253 after contralateral ischemia, compared with values for corresponding periods from the left kidney ranging from 138-266 before to 56-135 after arterial occlusion. Although urinary sodium concentration increased on the ipsilateral side in a manner typical of that observed in clinical forms of acute renal failure, this finding can only be regarded as being compatible with, but not convincing evidence for, a selective defect in transtubular transport of sodium. This is so because of the finding of a comparable average increase in urinary sodium concentration on the nonclamped side, a well-documented and predictable response to acute contralateral renal arterial constriction (17-20).

Additional evidence in support of ipsilateral injury of renal tubule function derives, however, from the findings that after release of occlusion, urine from the experimental kidney was colorless and when examined microscopically (in three rats) was found to contain large numbers of erythrocytes, renal tubule epithelial cells, and epithelial cell and granular casts. In contrast, urine from the contralateral control kidney, obtained simultaneously, regularly appeared dark yellow in color and contained neither cells nor formed elements.

Glomerular Dynamics in Acute Renal Failure 
TABLE II

Effect of $3 h$ of Ipsilateral Renal Ischemia on the Measured

\begin{tabular}{|c|c|c|c|c|c|c|c|c|c|c|c|c|c|}
\hline \multirow[b]{2}{*}{$\begin{array}{l}\text { Rat } \\
\text { no. }\end{array}$} & \multicolumn{13}{|c|}{ Preocclusion } \\
\hline & $\overline{A P}$ & SNGFR & $C_{A}$ & $C_{B}$ & SNFF & GPF & $\bar{P}_{G C}$ & $P_{T}$ & $\pi A$ & $\pi B$ & $P_{v F_{A}}$ & $P U F_{B}$ & $\frac{\pi E}{\bar{P}_{G C}-P_{T}}$ \\
\hline 14 & $m m \mathrm{Hg}$ & $\begin{array}{c}n l / \min \\
25.6 \\
27.0 \\
30.0\end{array}$ & & & & $n l / \min$ & $m m \mathrm{Hg}$ & $m m \mathrm{Hg}$ & $m m \mathrm{Hg}$ & $m m \mathrm{Hg}$ & $m m \mathrm{Hg}$ & $m m \mathrm{Hg}$ & \\
\hline 15 & 103 & $\begin{array}{l}27.5 \\
35.6 \\
34.6 \\
45.4 \\
36.8\end{array}$ & 5.4 & 9.2 & 0.41 & 66.6 & 46 & 11 & 17 & 40 & 18 & -5 & 1.14 \\
\hline 16 & 115 & $\begin{array}{l}38.1 \\
29.4 \\
19.5 \\
23.5 \\
17.4\end{array}$ & 5.9 & 8.9 & 0.34 & 113.1 & 46 & 10 & 20 & 38 & 16 & -2 & 1.06 \\
\hline 17 & 123 & \begin{tabular}{l|}
22.5 \\
13.7 \\
14.1 \\
10.5
\end{tabular} & 5.2 & 8.7 & 0.40 & 55.9 & 46 & 11 & 16 & 36 & 19 & -1 & 1.03 \\
\hline 18 & 118 & $\begin{array}{l}12.8 \\
20.9 \\
21.6 \\
17.7\end{array}$ & 5.9 & 8.7 & 0.32 & 39.7 & 44 & 14 & 20 & 36 & 10 & -6 & 1.20 \\
\hline 19 & 128 & $\begin{array}{l}20.1 \\
35.1 \\
30.5 \\
31.4 \\
33.5\end{array}$ & 5.7 & 8.1 & 0.30 & 67.8 & 52 & 12 & 19 & 32 & 21 & 8 & 0.80 \\
\hline 20 & 105 & $\begin{array}{l}32.6 \\
31.2 \\
50.4 \\
30.5 \\
30.1\end{array}$ & 5.5 & 8.9 & 0.38 & 85.4 & 45 & 14 & 18 & 38 & 13 & -7 & 1.22 \\
\hline 21 & 92 & $\begin{array}{l}35.5 \\
28.5 \\
37.3\end{array}$ & 5.2 & 8.8 & 0.41 & 86.9 & 46 & 13 & 16 & 37 & 17 & -4 & 1.12 \\
\hline 22 & 102 & $\begin{array}{l}32.9 \\
28.4 \\
26.0 \\
39.3\end{array}$ & 5.4 & 8.5 & 0.36 & 90.2 & 47 & 11 & 17 & 35 & 19 & 1 & 0.97 \\
\hline 23 & 112 & \begin{tabular}{l|l|}
31.2 & \\
19.6 & 25.7 \\
24.9 & 18.7 \\
\end{tabular} & 5.4 & 9.0 & 0.40 & 78.1 & 44 & 13 & 17 & 38 & 14 & -7 & 1.22 \\
\hline & 100 & 22.2 & 4.9 & 8.4 & 0.42 & 53.3 & 44 & 11 & 15 & 34 & 18 & -1 & 1.03 \\
\hline $\begin{array}{l}\text { Mean } \\
\pm \mathrm{SE} \\
\text { Mean } \Delta \\
\quad \text { from initial } \\
\pm \mathrm{SE} \\
P \text { value }\end{array}$ & $\begin{array}{r}110 \\
4\end{array}$ & $\begin{array}{r}27.5 \\
2.5\end{array}$ & $\begin{array}{l}5.5 \\
0.1\end{array}$ & $\begin{array}{l}8.8 \\
0.1\end{array}$ & $\begin{array}{l}0.37 \\
0.04\end{array}$ & $\begin{array}{r}73.7 \\
6.8\end{array}$ & $\begin{array}{r}46 \\
1\end{array}$ & $\begin{array}{c}12 \\
0.4\end{array}$ & $\begin{array}{l}18 \\
0.5\end{array}$ & $\begin{array}{l}36 \\
0.7\end{array}$ & $\begin{array}{r}16 \\
1\end{array}$ & $\begin{array}{r}-2 \\
1\end{array}$ & $\begin{array}{l}1.08 \\
0.04\end{array}$ \\
\hline
\end{tabular}

110 T. M. Daugharty, I. F. Ueki, P. F. Mercer, and B. M. Brenner 


\begin{tabular}{|c|c|c|c|c|c|c|c|c|c|c|c|c|}
\hline \multicolumn{13}{|c|}{ Postocclusion } \\
\hline \multirow[b]{2}{*}{$\overline{A P}$} & \multirow[b]{2}{*}{ SNGFR } & \multirow[b]{2}{*}{$C_{A}$} & \multirow[b]{2}{*}{$C_{E}$} & \multirow[b]{2}{*}{ SNFF } & \multirow[b]{2}{*}{ GPF } & \multirow[b]{2}{*}{$\bar{P}_{G C}$} & \multirow[b]{2}{*}{$P T$} & \multirow[b]{2}{*}{$\pi A$} & \multirow[b]{2}{*}{$\pi B$} & \multirow[b]{2}{*}{$P U F_{A}$} & \multirow[b]{2}{*}{$P_{U F_{E}}$} & \multirow{2}{*}{$\frac{\pi B}{\overline{P_{G C}-P_{T}}}$} \\
\hline & & & & & & & & & & & & \\
\hline \multirow[t]{3}{*}{$m m \mathrm{Hg}$} & $n l / \min$ & \multicolumn{2}{|c|}{$\mathrm{g} / 100 \mathrm{ml}$} & & $n l / \min$ & $m m \mathrm{Hg}$ & $m m \mathrm{Hg}$ & $m m \mathrm{Hg}$ & $m m \mathrm{Hg}$ & $m m \mathrm{Hg}$ & $m m \mathrm{Hg}$ & \\
\hline & $\begin{array}{l}13.5 \\
13.5\end{array}$ & & & & & & & & & & & \\
\hline & 18.9 & & & & & & & & & & & \\
\hline \multirow[t]{4}{*}{96} & 15.3 & 4.9 & 7.4 & 0.34 & 45.2 & 44 & 11 & 15 & 28 & 18 & 5 & 0.85 \\
\hline & 27.7 & & & & & & & & & & & \\
\hline & 22.5 & & & & & & & & & & & \\
\hline & $\begin{array}{l}34.3 \\
36.7\end{array}$ & & & & & & & & & & & \\
\hline \multirow[t]{5}{*}{123} & 30.3 & 5.8 & 8.5 & 0.32 & 95.3 & 46 & 14 & 19 & 35 & 13 & -3 & 1.09 \\
\hline & 17.0 & & & & & & & & & & & \\
\hline & 11.5 & & & & & & & & & & & \\
\hline & $\begin{array}{r}6.7 \\
10.3\end{array}$ & & & & & & & & & & & \\
\hline & & & & & . & & & & & & & \\
\hline \multirow{3}{*}{142} & 11.4 & 3.0 & 8.7 & 0.36 & 32.0 & 49 & 13 & 18 & 36 & 18 & 0 & 1.00 \\
\hline & 7.5 & & & & & & & & & & & \\
\hline & 6.7 & & & & & & & & & & & \\
\hline 107 & & 5.3 & 81 & & & & & & & & & \\
\hline & & & & 0.35 & 18.9 & 49 & 13 & 16 & 32 & 19 & 4 & 0.89 \\
\hline & $\begin{array}{l}15.3 \\
13.2\end{array}$ & & & & & & & & & & & \\
\hline & $\begin{array}{l}13.2 \\
11.0\end{array}$ & & & & & & & & & & & \\
\hline 123 & 13.2 & 4.8 & 7.6 & 0.37 & 35.8 & 52 & 12 & 15 & 29 & 25 & 11 & 0.72 \\
\hline & 19.1 & & & & & & & & & & & \\
\hline & 18.4 & & & & & & & & & & & \\
\hline & 24.8 & & & & & & & & & & & \\
\hline & 19.0 & & & & & & & & & & & \\
\hline 116 & 20.3 & 5.5 & 8.5 & 0.35 & 57.8 & 55 & 14 & 18 & 35 & 23 & 6 & 0.85 \\
\hline & 15.3 & & & & & & & & & & & \\
\hline & 13.8 & & & & & & & & & & & \\
\hline & 19.2 & & & & & & & & & & & \\
\hline & 12.9 & & & & & & & & & & & \\
\hline 93 & 15.3 & 5.1 & 7.7 & 0.34 & 45.3 & 37 & 13 & 16 & 30 & 8 & -6 & 1.25 \\
\hline & $\begin{array}{l}15.2 \\
24.6\end{array}$ & & & & & & & & & & & \\
\hline 100 & 19.9 & 5.6 & 8.5 & 0.34 & 58.3 & 47 & 14 & 18 & 35 & 15 & -2 & 1.06 \\
\hline & 19.7 & & & & & & & & & & & \\
\hline & 19.5 & & & & & & & & & & & \\
\hline & 21.8 & & & & & & & & & & & \\
\hline 101 & 20.4 & 5.4 & 8.5 & 0.37 & 55.8 & 47 & 12 & 17 & 35 & 18 & $\mathbf{0}$ & 1.00 \\
\hline & 7.6 & & & & & & & & & & & \\
\hline & 9.4 & & & & & & & & & & & \\
\hline & $\begin{array}{l}15.6 \\
11.2\end{array}$ & & & & & & & & & & & \\
\hline 100 & 11.0 & 4.8 & 8.4 & 0.43 & 25.6 & 44 & 15 & 15 & 34 & 14 & -5 & 1.17 \\
\hline 110 & 16.4 & 5.3 & 8.2 & 0.36 & 47.0 & 47 & 13 & 17 & 33 & 17 & 1 & 0.99 \\
\hline 5 & 2.1 & 0.1 & 0.1 & 0.01 & 6.9 & 2 & 0.4 & 0.5 & 0.9 & 2 & 2 & 0.05 \\
\hline+0.3 & $-41.3 \%$ & -0.2 & -0.5 & -0.019 & $-38.7 \%$ & +1 & +1 & -1 & -3 & +0.4 & +3 & -0.09 \\
\hline 3.1 & 3.1 & 0.1 & 0.2 & 0.014 & 3.7 & 1.6 & 0.6 & 0.6 & 1.2 & 2.0 & 2 & 0.06 \\
\hline$>0.5$ & $<0.001$ & $>0.2$ & $<0.025$ & $>0.2$ & $<0.001$ & $>0.5$ & $>0.5$ & $>0.2$ & $<0.025$ & $>0.5$ & $>0.1$ & $>0.10$ \\
\hline
\end{tabular}


Glomerular dynamics before ischemic injury. Table II and Fig. 2 summarize average values for several measures of nephron and microvascular function obtained before renal artery constriction in 10 normal hydropenic rats. SNGFR averaged $28 \mathrm{nl} / \mathrm{min}$. SNFF averaged 0.37 , with individual values ranging from 0.30 to 0.42 . Therefore, GPF, calculated using equation 3 , averaged $74 \mathrm{nl} / \mathrm{min}$. $\bar{P}_{G c}$ averaged $46 \mathrm{~mm} \mathrm{Hg}$, with individual values ranging from 44 to $52 \mathrm{~mm} \mathrm{Hg}$. Pressures measured at random sites in surface proximal convolutions averaged $12 \mathrm{~mm} \mathrm{Hg}$. Values for $P_{c}$ averaged $9.6 \pm 0.5 \mathrm{~mm} \mathrm{Hg}$. The hydrostatic pressure drop along surface afferent arterioles $\left(\overline{A P}-\bar{P}_{G C}\right)$ averaged $64 \pm 3 \mathrm{~mm} \mathrm{Hg}$, compared with a uniformly smaller pressure drop averaging $36 \pm 1 \mathrm{~mm} \mathrm{Hg}(P<0.001)$ along surface efferent arterioles $\left(\bar{P}_{G c}-P_{c}\right)$. Mean values for $R_{A}$ and $R_{E}$ are summarized in Fig. 2. On average, afferent arterioles were found to contribute $55 \%$ of the total resistance to blood flow ( $R_{T A}$, equation 8 ) to the level of the smallest accessible peritubular capillaries.

Microassay measurements of total protein concentration in preglomerular $\left(C_{A}\right)$ and efferent arteriolar $\left(C_{E}\right)$ plasma in 10 rats yielded values averaging 5.5 \pm 0.1 and $8.8 \pm 0.1 \mathrm{~g} / 100 \mathrm{ml}$, respectively. $\pi_{A}$ and $\pi_{E}$ calculated from these protein concentrations are shown in Table II. As given in equations 9 and 10, it is possible, from measurements of $\overline{\Delta P}$, that is $\bar{P}_{G C}-P_{T}$, together with these estimates of $\pi_{A}$ and $\pi_{E}$, to determine the magnitude of the transmembrane pressure difference favoring ultrafiltration $\left(P_{V F}\right)$ across afferent- and efferentmost portions of the glomerular capillary in each rat. As summarized in Table II, $\bar{P}_{G C}$ exceeded the sum of the opposing pressures $\left(P_{T}+\pi_{A}\right)$ at the afferent ends of glomerular capillaries by an average of $16 \pm 1 \mathrm{~mm} \mathrm{Hg}$. By the efferent ends this imbalance of pressures largely disappeared (Table II). For 10 rats the ratio $\pi_{E} /\left(\vec{P}_{G C}-P_{T}\right)$ averaged $1.08 \pm 0.04$, a value not significantly different from unity $(P>0.05)$, indicating that filtration pressure equilibrium obtained under these conditions.

Glomerular dynamics after ischemic injury. Without changing $\overrightarrow{A P}$, ischemic injury resulted in uniform and highly significant $(P<0.001)$ declines in SNGFR averaging $41 \%$ (Table II and Fig. 2). SNFF remained essentially constant; hence GPF fell in proportion to SNGFR. Despite the fall in SNGFR, note that neither $\bar{P}_{G c}$ nor $P_{T}$ changed significantly; hence $\Delta P$ and the pressure drop along the afferent arteriole $\left(\overline{A P}-\bar{P}_{G C}\right)$ remained unchanged. Ischemic injury likewise failed to produce substantial changes in $P_{c}$, values averaging $9.1 \pm 0.9 \mathrm{~mm} \mathrm{Hg}$. Accordingly, the pressure drop along the efferent arteriole $\left(\bar{P}_{G c}-P_{c}\right)$ also remained unchanged from preischemic values.
Rates of blood flow through single afferent (GBF) and efferent (EABF) arterioles on the renal cortical surface uniformly declined from average values of $147 \pm 13$ and $120 \pm 11 \mathrm{nl} / \mathrm{min}$ before ischemia to $95 \pm 13$ and $79 \pm 11 \mathrm{nl} / \mathrm{min}$ after injury, respectively. It follows from equations 6 and 7 that since these declines in arteriolar blood flow occurred without concomitant declines in the axial pressure drops along these arterioles, $R_{A}$ and $R_{B}$ were increased by ischemic injury (Fig. 2). These increases averaged $64.5 \pm 11.7 \%(P$ $<0.001)$ and $74.2 \pm 18.4 \% \quad(P<0.005)$, respectively. Since these increases in $R_{A}$ and $R_{E}$ were of similar magnitudes, the contribution of $R_{\mathbf{A}}$ to the total arteriolar resistance, $R_{T_{A}}$, remained essentially unchanged, averaging $57.4 \pm 1.1 \%$.

After ischemic injury, $C_{\boldsymbol{A}}$ remained unchanged (Table II) whereas $C_{E}$ tended to decline slightly, on average to $8.2 \pm 0.1 \mathrm{~g} / 100 \mathrm{ml}(P<0.025)$. Values for $\pi_{\boldsymbol{A}}$ and $\pi_{E}$ are given in Table II. Accordingly, the large and uniform declines in SNGFR occurred despite no significant mean declines in net ultrafiltration pressure at afferent $\left(P_{U F_{A}}\right)$ or efferent $\left(P_{U F_{E}}\right)$ ends of the glomerular capillary (Table II). The ratio $\pi_{E} /\left(\bar{P}_{G C}-P_{T}\right)$ averaged $0.99 \pm 0.05$, a value not different from unity $(P>0.05)$, indicating persistence of filtration pressure equilibrium. For paired data, the change in this ratio was likewise not significant statistically $(P>0.1)$.

\section{DISCUSSION}

In the Munich-Wistar rats examined for this study, $3 \mathrm{~h}$ of unilateral renal ischemia resulted in moderately severe reductions in ipsilateral GFR. Impairment in ipsilateral renal function was found to mimic the clinical disorder of postischemic acute renal failure in other respects, including most notably, the elaboration of a colorless urine rich in sodium, red blood, and renal tubule epithelial cells and epithelial cell casts. In addition, the capacity to reabsorb the same large fraction of the glomerular filtrate as the unclamped kidney was found to be markedly reduced. The declines in the measured values of GFR, shown not to be the consequence of any significant transtubular leak of inulin, involved cortical and juxtamedullary nephrons uniformly, in that the magnitude of reductions in whole kidney GFR and cortical SNGFR were similar in individual rats.

Glomerular ultrafiltration is governed by the imbalance of transcapillary hydrostatic and colloid osmotic pressure differences. At any point along a glomerular capillary the net driving force $\left(P_{T F}\right)$ is given by:

$$
\begin{aligned}
P_{U F} & =\Delta P-\Delta \pi \\
& =\left(P_{G C}-P_{T}\right)-\left(\pi_{G C}-\pi_{T}\right)
\end{aligned}
$$

where $P_{G c}$ and $P_{T}$ are the hydrostatic pressures in the 
glomerular capillary and proximal tubule, respectively, and $\pi \theta 0$ and $\pi r$ are the corresponding colloid osmotic pressures. Since tubule fluid is essentially protein-free, $\pi r$ is negligible and $\Delta \pi=\pi_{a c}$.

The rate of glomerular ultrafiltration per nephron (SNGFR) may be expressed as

$$
\begin{aligned}
\mathrm{SNGFR}=K_{f} \cdot \bar{P}_{U F}=k \cdot S \cdot \bar{P}_{U F} & =k \cdot S \cdot\left(\overline{\Delta P}-\bar{\pi}_{G C}\right)
\end{aligned}
$$

where $\bar{P}_{v y}$ is the mean driving pressure $\left(P_{y y}\right.$ averaged along the length of the capillary), equal to the difference between the mean transcapillary hydrostatic and oncotic pressure differences, $\overline{\Delta P}-\bar{\pi}_{\theta o} . K_{f}$, the ultrafiltration coefficient, is the product of the effective hydraulic permeability $(k)$ and surface area $(S)$ of the glomerular capillaries. Since in the present study $\bar{P}_{a c}$ and $P_{r}$ remained essentially unchanged after ischemic injury, so that $\overline{\Delta P}$ remained essentially unchanged, it follows from equation 14 that the decline in SNGFR following ischemia must have resulted from a decline in $K_{f}, \bar{P}_{v r}$, or both. Provided that $\bar{P}_{\delta r}$ could be evaluated from these pressure measurements, equation 14 would allow calculation of $K_{f}$ from measurements of $\bar{P}_{v}$ and SNGFR. However, under the conditions of filtration pressure equilibrium which prevailed in this study (equality of $\Delta P$ and $\pi_{\sigma o}$ at the efferent end of the glomerular capillary), it is impossible to estimate $\bar{P}_{v r}$, and thus $K_{r}$, due to the uncertainty in determining $\bar{\pi}_{a c}$. This uncertainty results from the fact that since the local rate of ultrafiltration is proportional to the local value of $P_{v r}, \pi g c$ will increase most rapidly at the afferent end of the capillary. As discussed in detail elsewhere (21), filtration pressure equilibrium requires that the profile of $\pi_{\theta 0}$ along a capillary be highly nonlinear, and allows for any number of nonlinear profiles to correspond to given measurements of $\pi_{A}$ and $\pi \pi^{21}$. Curves $A$ and $B$ in Fig. 3 show two possible profiles. For a given initial GPF, curve A corresponds to a larger value of $K_{r}$ than does curve B. In general, an increase in $K r$ above the minimum value required to yield equilibrium results in a more rapid approach to equilibrium (as in curve A) but essentially the same final value of $\pi_{a \sigma}$, measured as $\pi_{s}$. Since $\bar{P}_{v}$, is equal to the area between the $\Delta P$ and $\pi_{\theta \sigma}$ curves as plotted in Fig. 3, $\bar{P}_{0}$ and therefore $K_{t}$ cannot be uniquely determined from the available measurements under conditions of filtration pressure equilibrium.

The present study provides an excellent example of this uncertainty in determining $\bar{P}_{v} \boldsymbol{y}$ and $K_{f}$ under equilibrium conditions. As summarized in Fig. 2, SNGFR was markedly reduced by ischemic injury, whereas SNFF remained relatively unchanged. Accordingly, SNGFR must have declined in proportion to GPF, indicating, as previously reported $(2-4,21)$,

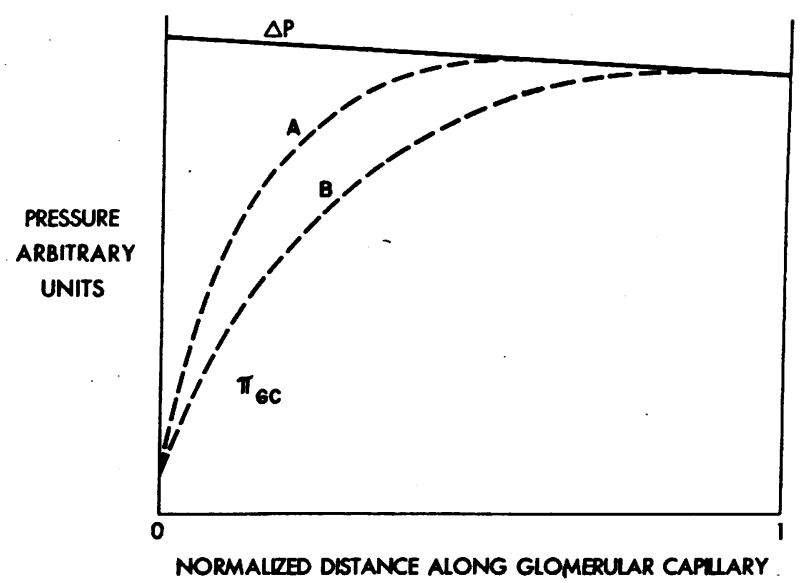

Figure 3 Hydrostatic and colloid osmotic pressure profiles along an idealized glomerular capillary. $\triangle P=P_{G \sigma}-P_{g}$. Since $\Delta \pi=\pi_{G C}-\pi \mathrm{r}$ and since $\pi \mathrm{r} \sim 0, \Delta \boldsymbol{\pi}=\pi_{\theta G}$.

that SNGFR is highly plasma-flow dependent. Some insight into the mechanism(s) responsible for this plasma-flow dependence of SNGFR is gained by reviewing the results of measurements of glomerular transcapillary hydrostatic and oncotic pressure obtained in this study. As noted, since values for $\overline{\Delta P}$ and $\pi_{A}$ after ischemic injury were essentially unchanged from preischemic values, the net driving pressure at the afferent end of the glomerular capillary $\left(P_{v r_{A}}\right)$ was likewise unchanged. Furthermore, equality of $\Delta P$ and $\pi_{B}$ obtained both before and after ischemia, indicating that the net driving pressure at the efferent end of the glomerular capillary $\left(P_{V r_{B}}\right)$ remained essentially zero throughout this study.

Although a term for the rate of plasma flow through the glomerulus does not appear explicitly in equation 14 , the rate of flow must modify the effective driving force for ultrafiltration. The mechanism whereby a decrease in GPF brings about a proportional decrease in SNGFR might involve flow-induced declines in $K_{r}, \bar{P}_{y y}$, or both. Fig. 3 helps to illustrate these possibilities. Let curve $B$ represent the actual $\pi a c$ profile before ischemic injury. If $K$, decreases in proportion to GPF, curve B will also represent the $\pi_{\sigma o}$ profile after ischemic injury. In this case, the area between the $\Delta P$ and $\pi \theta c$ curves (equal to $\vec{P}_{v r}$ ) will remain constant, and SNGFR will decrease solely as a result of the flowinduced decline in $K_{r}$. Alternatively, if $K_{r}$ remains unchanged after ischemia, the decrease in GPF will shift the $\pi_{G c}$ profile to the left, as from curve B to curve $A$ in Fig. 3, and the decline in SNGFR will result solely from the ensuing reduction in $\bar{P}_{\boldsymbol{v} r}$. Note that for both of the possibilities just considered, no changes in initial $\left(\pi_{A}\right)$ and final $\left(\pi_{E}\right)$ values of $\pi_{G C}$ are required. In the present study then, where a marked

Glomerular Dynamics in Acute Renal Failure 
TABLE III

[:Plasma-Flow Dependence of SNGFR. Comparison of Predicted with Observed Values

\begin{tabular}{ccc}
\hline & \multicolumn{2}{c}{ SNGFR } \\
\cline { 2 - 3 } Condition & Predicted & Observed \\
\hline \multirow{2}{*}{ Preischemia } & $n l / \min$ & $n l /$ min \\
& $24.7 \pm 2.2$ & $27.5 \pm 2.5$ \\
Postischemia & $(10)$ & $(10)$ \\
& $15.8 \pm 1.9$ & $16.4 \pm 2.1$ \\
& $(10)$ & $(10)$ \\
\hline
\end{tabular}

Observed SNGFR values are given as means \pm SE. Predicted refers to values calculated using the model (21), assuming $K_{f}$ to equal $0.08 \mathrm{nl} /(\mathrm{s} \cdot \mathrm{mm} \mathrm{Hg})$ and to be constant for both conditions. An axial pressure drop along the glomerular capillary of $1 \mathrm{~mm} \mathrm{Hg}$ has been assumed, the justification for which is given elsewhere (2). Numbers in parentheses refer to $n$ animals.

decline in SNGFR was accomplished without appreciable changes in $\pi_{A}, \pi_{E}$, or $\Delta P$, the persistence of filtration pressure equilibrium makes it impossible to determine the relative contributions of changes in $K_{f}$ and $\bar{P}_{U F}$ to the total change in SNGFR.

Nevertheless, it is possible to gain considerable insight into the mechanisms responsible for the observed plasma-flow dependence of SNGFR after ischemic injury by use of a recently developed mathematical model (21) which simulates the known dynamics of glomerular ultrafiltration. In this model, conservation of mass and the Starling hypothesis have been used to derive a differential equation giving the rate of change of protein concentration with distance along an idealized glomerular capillary. The numerical solution to this equation, given in detail elsewhere (21), can be used to compute $\pi_{G C}$ profiles for given values of $C_{A}, K_{f}, \overline{\Delta P}$, and GPF. Application of the model to the present study is readily accomplished in that values for all of the necessary inputs except $K_{f}$ were measured. For reasons already discussed, a value for $K_{f}$ cannot be determined under conditions of filtration pressure equilibrium. A unique value for $K_{f}$ of the glomerulus of this mutant rat has, however, recently been obtained by Deen, Troy, Robertson, and Brenner (4) under conditions of very high GPF, which had the desired effect of preventing achievement of filtration pressure equilibrium. Under these disequilibrium conditions only one $\pi_{G C}$ profile can fit the experimental data, yielding only one value of $K_{t}$. Moreover, this unique value of $K_{f}, 0.08 \mathrm{nl} /(\mathrm{s} \cdot \mathrm{mm} \mathrm{Hg})$, was found to be essentially constant despite almost twofold variations in GPF. Of particular importance to the present study, this same value of $K_{f}$ was found to be sufficiently large to yield equilibrium at the lower rates of GPF which obtain in normal hydropenic rats (4). As shown in Table III, use of this same $K_{f}$ value together with measured values of $C_{\Delta}, \overline{\Delta P}$, and GPF from the 10 normal hydropenic rats studied before ischemic injury in the present study leads to remarkably close agreement between predicted and observed values for $\mathrm{SN}$ GFR. Note that similarly close agreement between predicted and observed values obtains for inputs measured after ischemic injury. Since in the latter calculation $K_{f}$ has been held constant at the preischemic value of $0.08 \mathrm{nl} /(\mathrm{s} \cdot \mathrm{mm} \mathrm{Hg})$, the present evidence suggests, but by no means establishes, that the decline in SNGFR after ischemic injury was mediated solely by a decline in $\bar{P}_{V F}$ resulting from a plasma-flow induced shift in the $\pi_{G C}$ curve so that equality with $\overline{\Delta P}$ is achieved at a site nearer the afferent end of the glomerular capillary than was the case before ischemia (analogous to a shift in the $\pi_{G C}$ profile from curve $\mathrm{B}$ to curve A in Fig. 3).

The present findings thus provide a potentially ubiquitous explanation to account, at least in part, for the fall in GFR that regularly occurs in a variety of forms of acute renal failure. In this study, the observed decline in SNGFR could be attributed solely to the decline in $\bar{P}_{V F}$, the latter due to a rise in $\bar{\pi}_{G C}$. The present studies by no means exclude the possibility that $\bar{P}_{\text {or }}$ might also fall due to a decline in $\overline{\Delta P}$ (equation 14). While not observed in the present study, such a decline in $\overline{\Delta P}$ (due either to a fall in $\bar{P}_{G c}$, a rise in $P_{r}$, or both) would be expected to result in reductions in filtration rate more severe than those produced in the present study (that is, due to a fall in GPF alone). Likewise, more severe reductions in filtration rate would be expected were a fall in GPF to be accompanied by a concomitant decline in $K_{f}$. Obviously, were declines in $\overline{\Delta P}$ or $K_{f}$, or both, to be superimposd on a flow-induced decline in $\bar{P}_{U F}$, GFR would then be expected to fall more than in proportion to the fall in GPF (i.e., filtration fraction would fall).

It should be readily evident from the foregoing that glomerular ultrafiltration is determined primarily by a dynamic interplay of pressures and flows within and across the glomerular capillary wall. Until now, an assessment of all of the critical pressures and flows has been lacking in experimental studies of the defect in glomerular ultrafiltration in acute renal failure, largely because of the inaccessibility of the glomerulus to direct examination in the mammal. Nevertheless, an extensive body of literature has accumulated on this topic which, in general, has identified alterations in the glomerular microcirculation as being causally responsible, at least in part, for the observed defects in ultrafiltration (a comprehensive bibliography is given in [22]).

In the present study, reductions in GPF occurred in the absence of concomitant declines in $\bar{P}_{G C}$ and were, 
therefore, the result of proportional increases in $R_{A}$ and $R_{E}$. These increases in resistance are presumed to correspond to reductions in the luminal diameters of afferent and efferent arterioles induced by renal ischemia. Of interest, Sheehan and Davis (23) and others more recently (24-28) have called attention to the persistence of impaired organ blood flow (kidney, brain, heart) following relief of temporary, but severe, arterial occlusion (the so-called no-reflow phenomenon). Leaf has suggested (25) and he and co-workers $(27,28)$ and others (26) have provided evidence to indicate that capillary endothelial cells tend to swell after severe ischemia and that such swelling might account, at least in part, for the persistence of impaired organ perfusion. In support of this possibility, perfusion of ischemic organs with solutions of hypertonic mannitol was found by these workers $(27,28)$ to improve organ blood flow, presumably by an effect of this hypertonic, relatively impermeant solute to reduce postischemic cell swelling. Whether cell swelling accounts for the reduction in GPF and the increases in $R_{A}$ and $R_{E}$ observed after ischemic injury in the present study remains to be determined. Based on preliminary observations using light and electron microscopy, however, we have been unable to demonstrate swelling of endothelial cells in glomerular capillaries of several kidneys which exhibited typical alterations in GPF, SNGFR, $R_{A}$, and $R_{E}$. Moreover, additional preliminary evidence has been obtained to indicate that these postischemic alterations in GPF, SNGFR, and $R_{A}$ and $R_{B}$ can be reversed by expansion of plasma volume with donor rat plasma ( $2.5 \%$ body weight), an effect clearly not attributable to the osmotic action of hypertonic solute. More work will obviously be required before the precise mechanism(s) responsible for the postischemic increase in microvascular resistances observed in the present study can be established. It seems relatively clear, however, that these increases in resistance to blood flow constitute a fundamental defect in this form of acute renal failure.

\section{ACKNOWLEDGMENTS}

The authors wish to thank Ms. Delys Nicholas, Julia Troy, Carolyn Wong, and Mr. Robert Surface for excellent technical assistance and Ms. Meredith Clark for expert secretarial assistance. We also express our gratitude to Doctors William M. Deen and Channing Robertson for helpful advice.

These studies were supported in part with funds from the U. S. Public Health Service (AM 13888) and the Veterans Administration.

\section{REFERENCES}

1. Brenner, B. M., J. L. Troy, and T. M. Daugharty. 1971. The dynamics of glomerular ultrafiltration in the rat. J. Clin. Invest. 50: 1776.
2. Brenner, B. M., J. L. Troy, T. M. Daugharty, W. M. Deen, and C. R. Robertson. 1972. Dynamics of glomerular ultrafiltration in the rat. II. Plasma-flow dependence of GFR. Am. J. Physiol. 223: 1184.

3. Robertson, C. R., W. M. Deen, J. L. Troy, and B. M. Brenner. 1972. Dynamics of glomerular ultrafiltration in the rat. III. Hemodynamics and autoregulation. $\mathrm{Am}$. J. Physiol. 223 : 1191.

4. Deen, W. M., J. L. Troy, C. R. Robertson, and B. M. Brenner. 1973. Dynamics of glomerular ultrafiltration in the rat. IV. Determination of the ultrafiltration coefficient. J. Clin. Invest. 52: 1500.

5. Brenner, B. M., and J. H. Galla. 1971. Influence of post-glomerular hematocrit and protein concentration on rat nephron fluid transfer. Am. J. Physiol. 220: 148.

6. Daugharty, T. M., I. F. Ueki, D. P. Nicholas, and B. M. Brenner. 1972. Comparative renal effects of isoncotic and colloid-free volume expansion in the rat. Am. J. Physiol. 222 : 225.

7. Brenner, B. M., T. M. Daugharty, I. F. Ueki, and J. L. Troy. 1971. Quantitative assessment of proximal tubule function in single nephrons of the rat kidney. $A m$. $J$. Physiol. 220: 2058.

8. Gottschalk, C. W., F. Morel, and M. Mylle. 1965. Tracer microinjection studies of renal tubular permeability. Am. J. Physiol. 209: 173.

9. Wiederhielm, C. A., J. W. Woodbury, S. Kirk, and R. F. Rushmer. 1964. Pulsatile pressures in the microcirculation of frog's mesentery. Am. J. Physiol. 207 : 173.

10. Falchuk, K. H., and R. W. Berliner. 1971. Hydrostatic pressures in peritubular capillaries and tubules in the rat kidney. Am. J. Physiol. 220: 1422.

11. Brenner, B. M., J. L. Troy, and T. M. Daugharty. 1972. Pressures in cortical structures of the rat kidney. Am. J. Physiol. 222: 246.

12. Vurek, G. G., and S. E. Pegram. 1966. Fluorometric method for the determination of nanogram quantities of inulin. Anal. Biochem. 16: 409.

13. Führ, J., J. Kaczmarczyk, and C. D. Krüttgen. 1955. Eine einfache colorimetrische Methode zur Inulin Bestimmung für Nierenclearanceuntersuchungen bei Stoffwechselgesunden und Diabetikern. Klin. Wochenschr. 33: 729 .

14. Brenner, B. M., K. H. Falchuk, R. I. Keimowitz, and R. W. Berliner. 1969. The relationship between peritubular capillary protein concentration and fluid reabsorption by the renal proximal tubule. J. Clin. Invest. $48: 1519$.

15. Lowry, O. H., N. J. Rosebrough, A. L. Farr, and R. J. Randall. 1951. Protein measurement with the Folin phenol reagent. J. Biol. Chem. 193: 265.

16. Landis, E. M., and J. R. Pappenheimer. 1963. Exchange of substances through the capillary walls. Handb. Physiol. Circulation. 2: 961.

17. Stein, R. M., R. G. Abramson, D. D. Bercovitch, and M. F. Levitt. 1965. Effects of unilateral renal arterial constriction on tubular reabsorption of sodium and water during an osmotic diuresis. J. Clin. Invest. 44: 1720.

18. Zweig, S. M. 1971. Failure of physical factors to account for unilateral increases in urine flow rate and sodium excretion after acute partial renal artery constriction of the opposite kidney. Abstracts of the American Society of Nephrology. 5: 93.

Glomerular Dynamics in Acute Renal Failure 
19. Kramer, P., and B. Ochwadt. 1972. Sodium excretion in Goldblatt hypertension. Long-term separate kidney function studies in rats by means of a new technique. Pfluegers Arch. Eur. J. Physiol. 332: 332.

20. Conger, J. D., E. Bartoli, and L. E. Earley. 1973. Na reabsorption in the rat kidney during contralateral renal artery constriction, ureteral obstruction or renal pedicle ligation. Clin. Res. 21 : 682.

21. Deen, W. M., C. R. Robertson, and B. M. Brenner. 1972. A model of glomerular ultrafiltration in the rat. Am. J. Physiol. 223: 1178.

22. Oken, D. E. 1971. Editorial. Nosologic considerations in the nomenclature of acute renal failure. Nephron. 8: 505.

23. Sheehan, H. L., and J. C. Davis. 1959. Renal Ischaemia with failed reflow. J. Pathol. Bacteriol. 78: 105.
24. Ames, A., III, R. L. Wright, M. Kowada, J. M. Thurston, and G. Majno. 1968. Cerebral ischemia. II. The no-reflow phenomenon. Am. J. Pathol. 52: 437.

25. Leaf, A. 1970. Regulation of intracellular fluid volume and disease. Editorial. Am. J. Med. 49: 291.

26. Summers, W. K., and R. L. Jamison. 1971. The no reflow phenomenon in renal ischemia. Lab. Invest. 25: 635.

27. Flores, J., D. R. DiBona, C. H. Beck, and A. Leaf. 1972. The role of cell swelling in ischemic renal damage and the protective effect of hypertonic solute. $J$. Clin. Invest. 51: 118.

28. Willerson, J. T., W. J. Powell, Jr., T. E. Guiney, J. J. Stark, C. A. Sanders, and A. Leaf. 1972. Improvement in myocardial function and coronary blood flow in ischemic myocardium after mannitol. J. Clin. Invest. $51: 2989$. 